\title{
Geociências
}

\section{Análise sedimentológica e de proveniência de sedimentos fluviais nas cabeceiras do rio das Velhas, município de Ouro Preto, MG}

\author{
(Sedimentologic and provenance analysis of the Rio das \\ Velhas upstream fluvial sediments, Ouro Preto - MG)
}

\author{
Cláudio Eduardo Lana \\ Eng. Geólogo, MSc, Centro de Ciências Agrárias, Ufes \\ E-mail: claudiolana@cca.ufes.br \\ Paulo de Tarso Amorim Castro \\ Geólogo, Dr., Departamento de Geologia, UFOP \\ E-mail:paulo_de_tarso@degeo.ufop.br
}

\section{Resumo}

Esse trabalho apresenta os resultados do estudo sedimentológico em um segmento fluvial do alto rio das Velhas, na região de Ouro Preto, Minas Gerais. Os sedimentos foram coletados em duas barras e duas séries de transectos distribuídos ao longo do canal. A granulometria, mineralogia/petrografia e o grau de arredondamento dos clastos foram analisados. Os resultados indicaram que o segmento fluvial pode ser classificado como um ambiente cascalhoso, com predominância de clastos subangulosos a subarredondados de quartzo, hematita, metadiabásio, canga e quartzito. Esses dados indicam uma contribuição associada a veios de quartzo, às formações ferríferas do Grupo Itabira, às rochas do Grupo Caraça e a pequenos corpos máficos intrusivos.

Palavras-chave: Sedimentologia, proveniência de clastos, cabeceiras, rio das Velhas, Minas Gerais.

\begin{abstract}
This work deals with a sedimentologic study of a creek segment of the rio das Velhas headwaters, in the region of Ouro Preto, Minas Gerais. Samples were collected on two bars and on two transects along the channel. The petrography/mineralogy, grain size and roundness of the clasts have been studied. The results show that the river segment can be classified as coarsegrained (pebbly) environment, with predominance of sub-rounded to sub-angular clasts of quartz, hematite, metadiabase, laterite and quartzite. These data show that the source rocks are quartz veins, banded iron formations of Itabira Group, metasedimentary rocks of Caraça Group and small intrusive mafic bodies.
\end{abstract}

Keywords: Sedimentology, clast provenance, headwaters, rio das Velhas, Minas Gerais. 


\section{Introdução}

Os sistemas fluviais têm grande capacidade erosiva e transportadora. Investigar os fenômenos de erosão e deposição permite concluir sobre a dinâmica hidrológica dos cursos d’água (Schumm, 1977).

Dentro do contexto da dinâmica hidrológica e das taxas de erosão e deposição, existem variáveis que não podem ser deixadas de lado, incluindo, aqui, a granulometria, o grau de arredondamento e a filiação petrográfica (ou mineralógica) dos clastos.

Essas variáveis podem permitir a identificação das áreas-fonte e da distância de transporte dos clastos. Nesse caso, é possível compreender várias questões, como, por exemplo, as causas do assoreamento dos canais.

Os principais objetivos desse trabalho foram:

- Efetuar a análise sedimentar de um segmento fluvial nas cabeceiras do rio das Velhas.

- Relacionar entre si as informações referentes à granulometria dos sedimentos, seu grau de arredondamento e respectiva classificação petrográfica ou mineralógica.

- Associar os resultados obtidos à distância entre o local de coleta e as áreas-fonte das rochas e minerais presentes no leito.

- Analisar as possibilidades de contribuição antrópica para a erosão das áreas-fonte e deposição no leito do canal.

A base cartográfica utilizada foi uma compilação da geologia regional, em escala 1:250.000 (Moura, 2000).

A área está situada à montante do distrito de São Bartolomeu, município de Ouro Preto - MG, próximo às nascentes do rio das Velhas.

Em termos de geologia regional, localiza-se nos domínios do Quadrilátero Ferrífero. Porém a bacia de contribuição do segmento estudado disseca somente rochas dos supergrupos Rio das Velhas e Minas. O primeiro é constituído de rochas metavulcânicas ultramáficas, máficas e félsicas intercaladas a rochas metassedimentares, tais como BIF's do tipo Algoma, rochas carbonáticas e siliciclásticas; já o segundo, é composto por quartzitos, metaconglomerados, metapelitos, itabiritos e mármores e, esporadicamente, rochas metavulcânicas (síntese extraída de Alkmim \& Marshak, 1998).

A Figura 1 apresenta o posicionamento do alto rio das Velhas em relação às bacias do rio das Velhas e São Francisco. As principais vias de acesso, bem como a rede de drenagem e a geologia simplificada da bacia de contribuição à área de estudo, também podem ser observadas.

\section{Materiais e métodos Coleta}

A amostragem foi realizada na parte emersa de duas barras e, também, diretamente sobre o leito, em duas séries de transectos, cada uma composta por três linhas de amostragem (Figura 2).

A seguir, é feita uma descrição detalhada da distribuição dos pontos de coleta (esquema ilustrado na Figura 3):

- Transectos - as amostras foram coletadas no limite da margem esquerda $\left(\mathrm{M}_{\mathrm{e}}\right)$, direita $\left(\mathrm{M}_{\mathrm{d}}\right)$ e centro (C), ao longo de três linhas perpendiculares ao fluxo d'água. $\mathrm{O}$

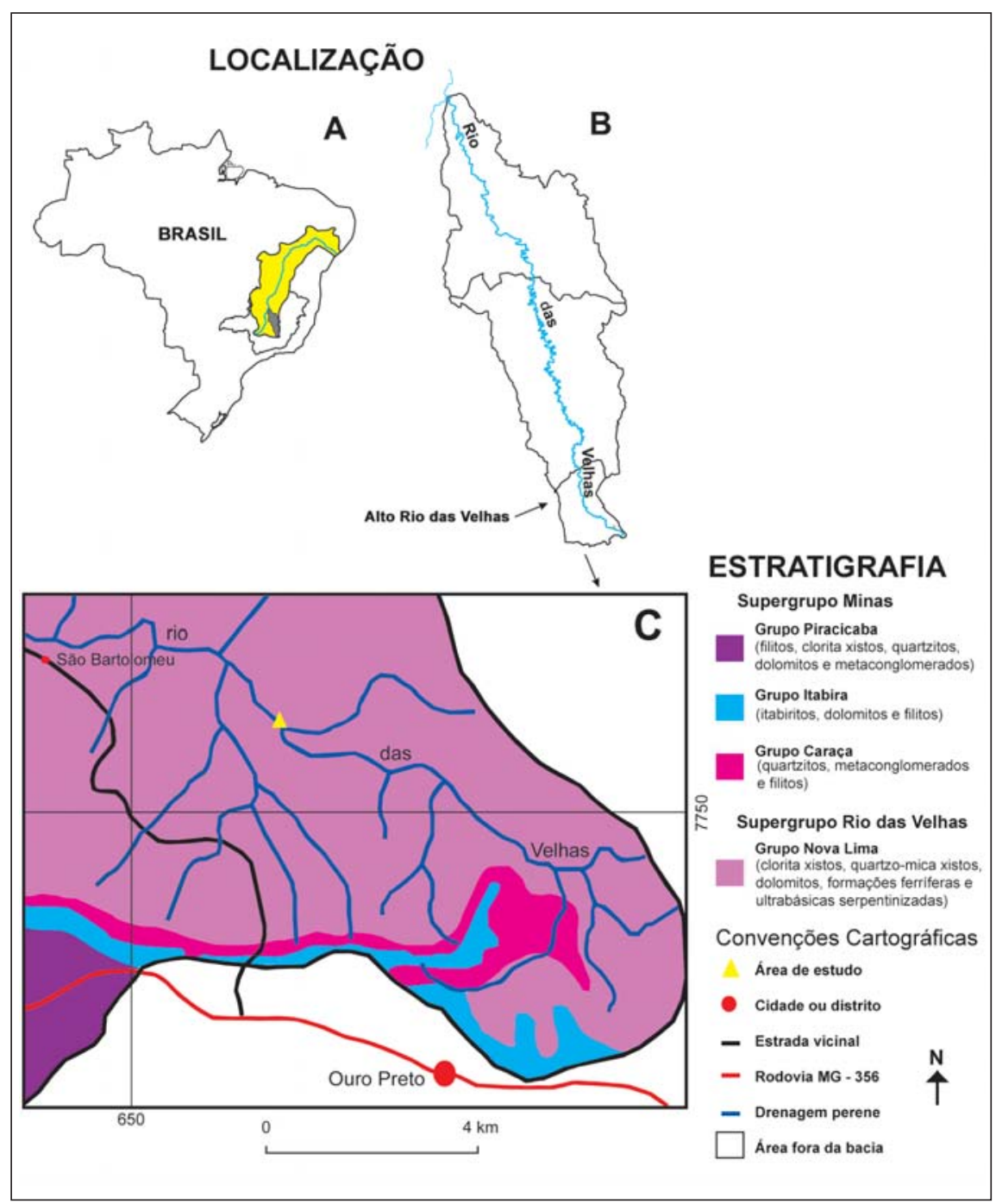

Figura 1 - Posicionamento do alto rio das Velhas em relação às bacias do rio das Velhas (B) e do rio São Francisco (A). No detalhe, o mapa geológico simplificado da bacia de contribuição à área de estudo (C). Adaptado a partir de Moura (2000). 


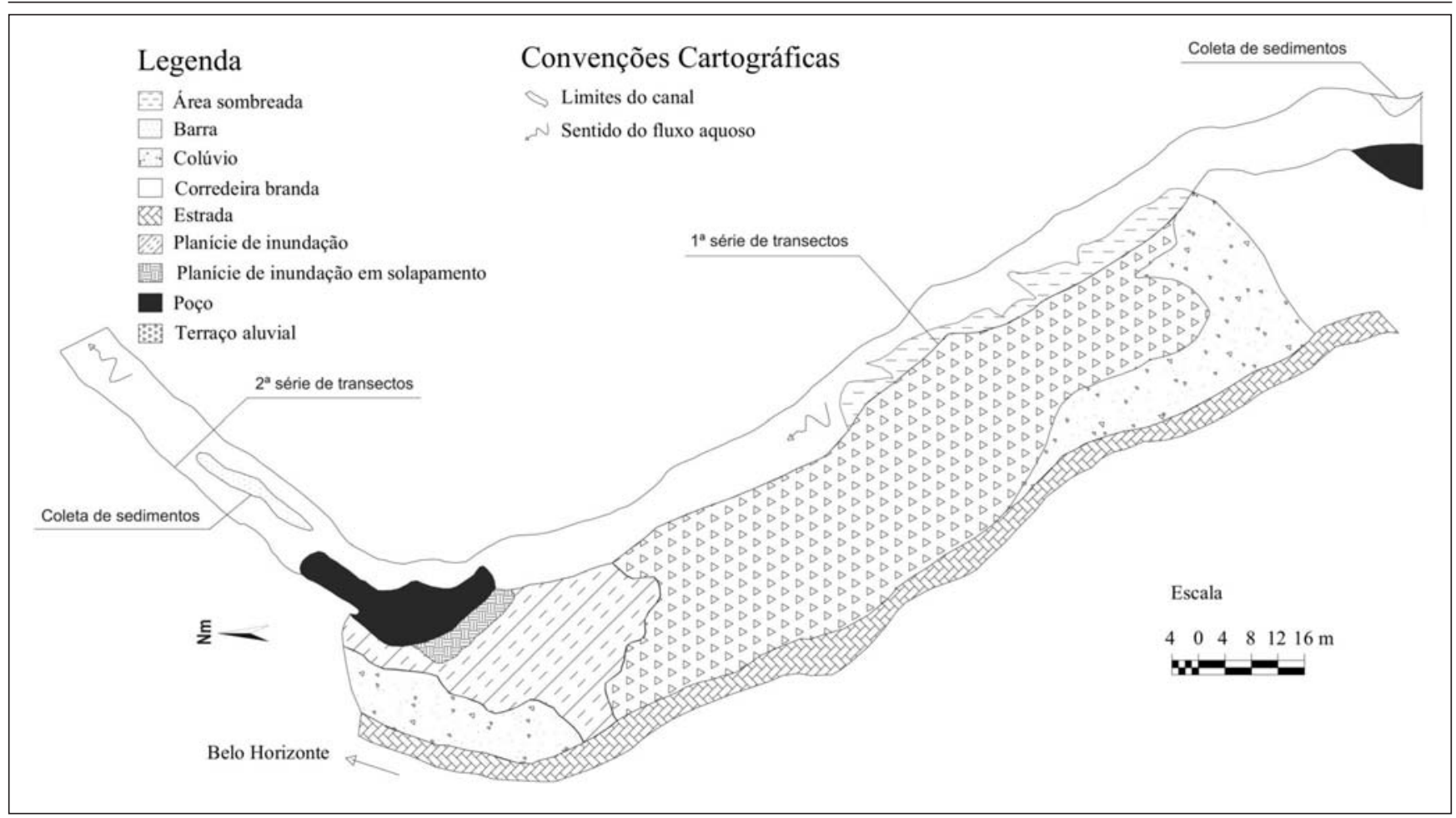

Figura 2 - Mapa de detalhe do segmento estudado, mostrando os locais de amostragem de sedimentos. Modificado de Lana (2004). Escala de levantamento 1:400.

espaçamento entre essas linhas foi estipulado como sendo equivalente à largura média do canal $\left(\mathrm{L}_{\mathrm{m}}\right)$.

- Barras - as amostras foram coletadas ao longo da linha central da barra no sentido longitudinal (crista) e o seu espaçamento (E) foi o valor da largura máxima da barra $\left(\mathrm{L}_{\text {max }}\right)$.

Amostrou-se, aproximadamente, 1 litro da porção mais superficial de cada ponto.

\section{Análise Granulométrica}

As amostras foram classificadas seguindo os limites convencionais de classes granulométricas (p.ex.: Mabesoone, 1968).

Os clastos maiores que $8 \mathrm{~mm}$ foram classificados por meio do classificador ilustrado na Figura 4. Ao final, cada conjunto de clastos de uma dada classe granulométrica foi pesado.

Apesar do grande número de clastos inferiores a $8 \mathrm{~mm}$ (Figura 5), a sua

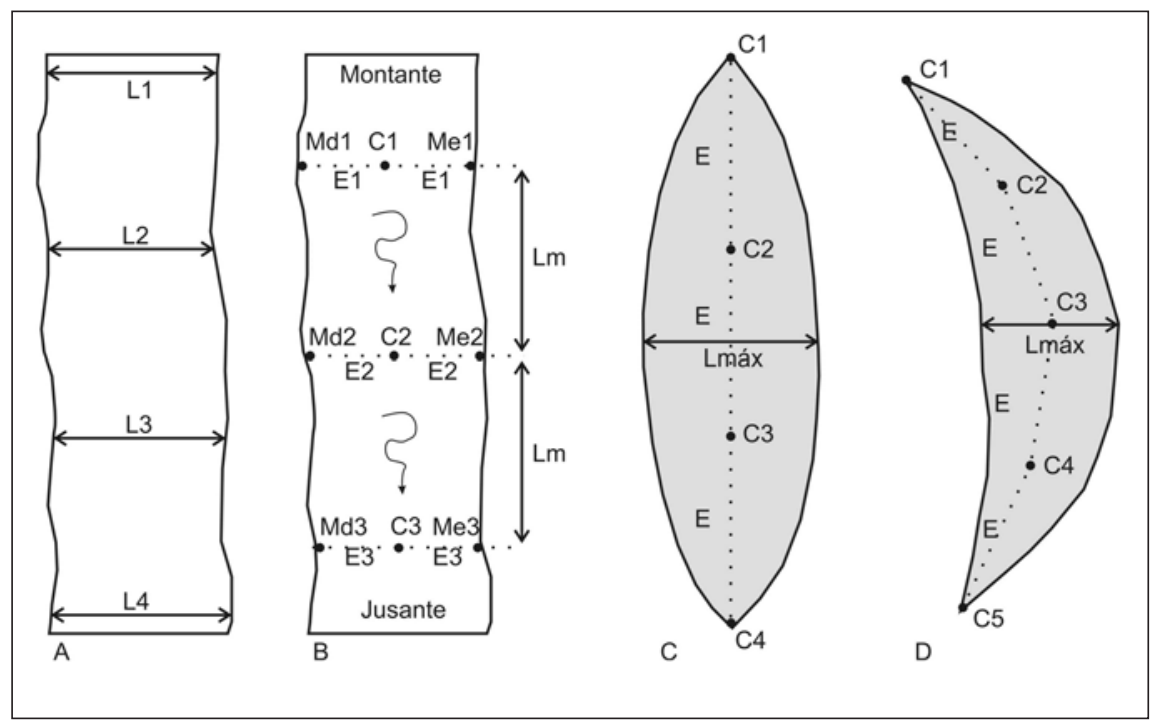

Figura 3 - Diagramas de coleta de sedimento. Em A, tem-se a medida da largura de alguns trechos do canal, para obtenção do valor médio $\left(\mathrm{L}_{m}\right)$. Em $B$, tem-se a distribuição dos pontos de coleta $\left(M_{e}, C\right.$ e $M_{d}$ - Margem Esquerda, Centro e Margem Direita), segundo um espaçamento uniforme entre as amostras $\left(E_{1}, E_{2}, E_{3}\right)$ e entre os transectos $\left(L_{m}\right)$. Em $C$ e $D$, está representada a largura máxima da barra $\left(L_{\text {máx }}\right)$, que determina o valor do espaçamento (E) entre as amostras $\left(\mathrm{C}_{1}, \mathrm{C}_{2}, \mathrm{C}_{3}\right.$, etc.).

presença não foi muito significativa em termos volumétricos, tendo os mesmos representado, no máximo, $10 \%$ das amostras. Como as análises macroscópicas posteriores foram realizadas para cada grão, a caracterização dos clastos foi inviável devido às suas dimensões reduzidas. 
Análise sedimentológica e de proveniência de sedimentos fluviais nas cabeceiras do rio das Velhas...

\section{Análise petrográfica e mineralógica}

A petrografia (ou mineralogia) dos clastos agrupados em cada classe granulométrica foi analisada com uma lupa com aumento de 20x.

A partir dessa análise, foram criados subconjuntos dentro de cada grupo de mesma granulometria.

A análise petrográfica seguiu os passos apresentados em Costa (1973) e a mineralógica, em Dana (1960).

\section{Avaliação do grau de arredondamento}

Cada clasto passou, também, por uma análise de grau de arredondamento, feita por comparação com os padrões adotados por Tucker (1981). Para cada mineral ou rocha, em uma mesma classe granulométrica, foram contados quantos apresentavam o mesmo grau de arredondamento.

Os dados referentes à análise de granulometria, grau de arredondamento, petrografia e mineralogia são apresentados na forma de gráficos (Figuras 5, 6e 7).

\section{Resultados}

Foram analisados ao todo 1445 clastos, entre os quais se identificaram 3 tipos de minerais e 13 de rochas (Figura 8).
De acordo com a classificação mineralógica e petrográfica, os minerais e rochas mais abundantes nas amostras são o quartzo (710 indivíduos), seguido pela hematita compacta (258), rocha máfica - provavelmente metadiabásio (135), canga (118) e quartzito (115).

Nesses cinco materiais geológicos, predominam dois graus de arredondamento: quartzo - subanguloso; hematita compacta, rocha máfica, canga e quartzito - subarredondados (Figura 6).

Os seixos muito grossos, apesar de pouco numerosos, predominam em termos de peso na maioria das amostras (Figura 5).

Nas amostras dos dois transectos, há predominância de clastos mais angulosos na margem esquerda (Figura 7). Já, na porção central do leito e na margem direita, a distribuição dos graus de arredondamento é mais eqüitativa, ocorrendo até clastos bem arredondados.

\section{Discussão}

Os clastos maiores só não dominam o peso das amostras quando representam fragmentos de rochas ou minerais de baixa densidade ou bastante intemperizados (p.ex., fragmentos de xistos do Grupo Nova Lima).

A margem esquerda do canal representa a faixa de maior energia de fluxo. Portanto acredita-se que o menor grau

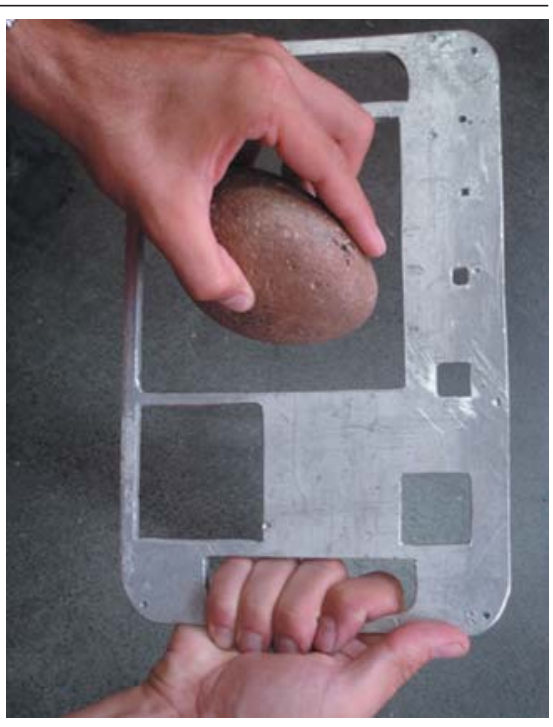

Figura 4 - Classificação granulométrica usando classificador de seixos.

de arredondamento dos clastos ali encontrados seja devido ao curto tempo de permanência num mesmo ponto, associado ao choque com os demais e conseqüente fraturamento. À medida que se caminha para a margem direita do canal, o fluxo se torna menos energético e os sedimentos permanecem estáticos por um maior tempo. Portanto a abrasão tende a torná-los mais arredondados, conforme pode ser observado na Figura 7.

Com relação à aplicação de rochas e minerais no calçamento e cobertura de estradas vicinais, foi possível perceber que há uma preferência pelo estéril de mineradoras de ferro (rico em fragmen-

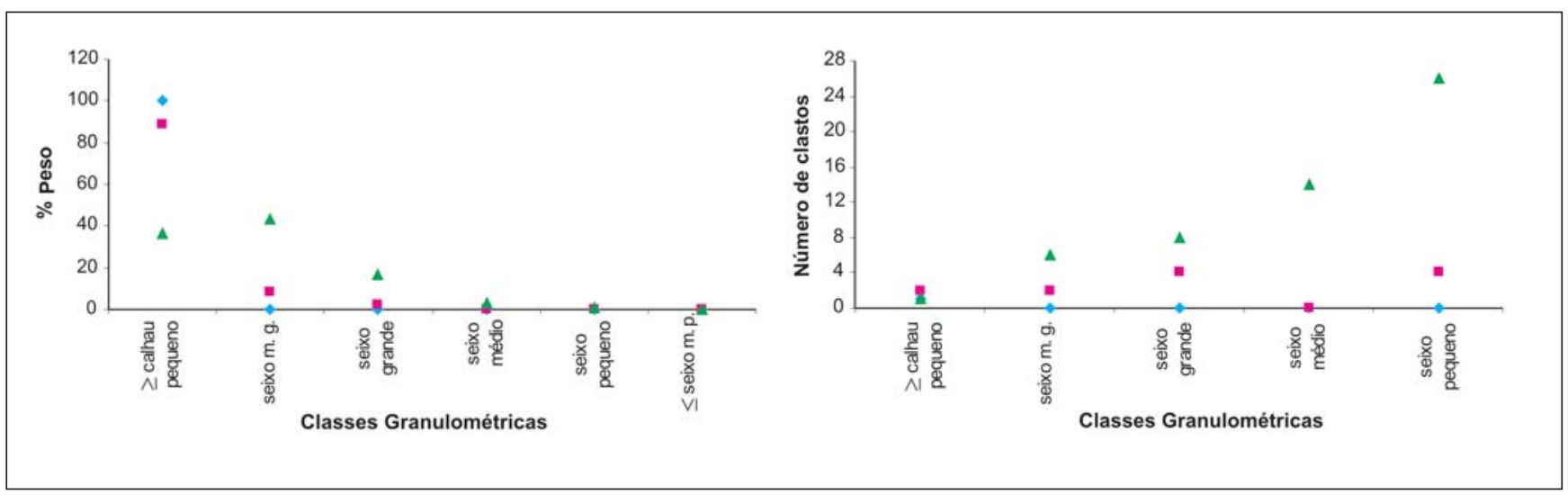

Figura 5 - Representatividade de cada classe granulométrica em relação ao peso total das amostras (esquerda) e ao número total de clastos (direita) do $1^{\circ}$ transecto a montante. Extraído de Lana (2004).

Abreviaturas e símbolos: m.g. = muito grande, m.p. = muito pequeno, $\leq=$ menor ou igual a, $\geq=$ maior ou igual a, círculo azul = margem esquerda, quadrado vermelho $=$ centro e triângulo verde $=$ margem direita . 


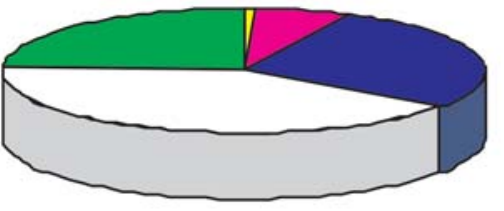

Quartzo

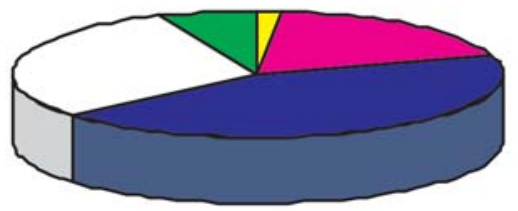

Canga

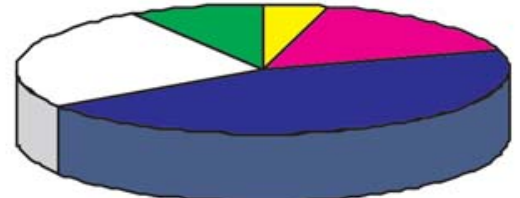

Hematita

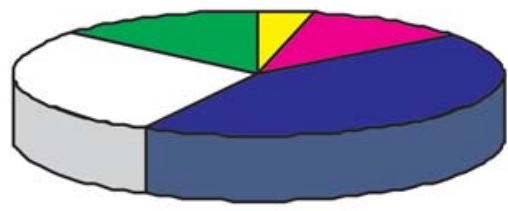

Quartzito

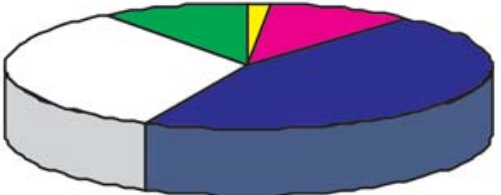

Máfica

\section{LEGENDA}

Bem arredondados

Arredondados

Subarredondados

Subangulosos

Angulosos

Figura 6 - Variação dos graus de arredondamento dentro do conjunto dos clastos mais abundantes na área de trabalho. Extraído de Lana (2004).
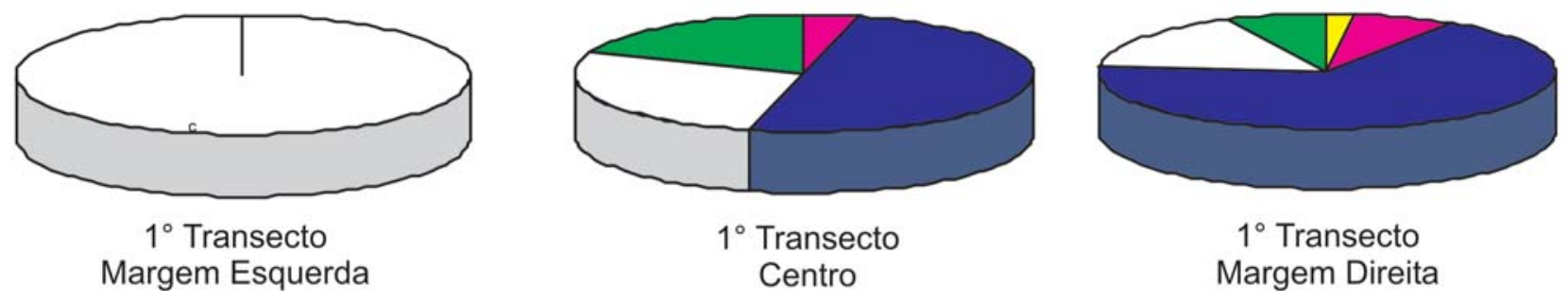

$1^{\circ}$ Transecto

$1^{\circ}$ Transecto

Centro

Margem Direita

Figura 7 - Variação dos graus de arredondamento de todos os clastos, indiscriminadamente, nas amostras do $1^{\circ}$ transecto a montante. É válida a mesma legenda da figura anterior. Extraído de Lana (2004).

tos de hematita e itabirito muito angulosos, encontrados no máximo na fração seixo), seguido pelo quartzo de veio. Esse último é extraído em áreas de empréstimo a menos de $500 \mathrm{~m}$ do segmento fluvial estudado e ocorre em frações superiores a seixo fino.

Os clastos de rochas máficas analisados nesse trabalho são mais resistentes ao choque mecânico do que outros materiais identificados, como o quartzo de veio e o quartzito, devido à sua alta tenacidade, ao baixo grau de fraturamento e à alta coesão dos seus minerais. Apesar dessa característica, seu uso em estradas vicinais não é comum.

A extração de quartzito e o calçamento das estradas são as possíveis fon-

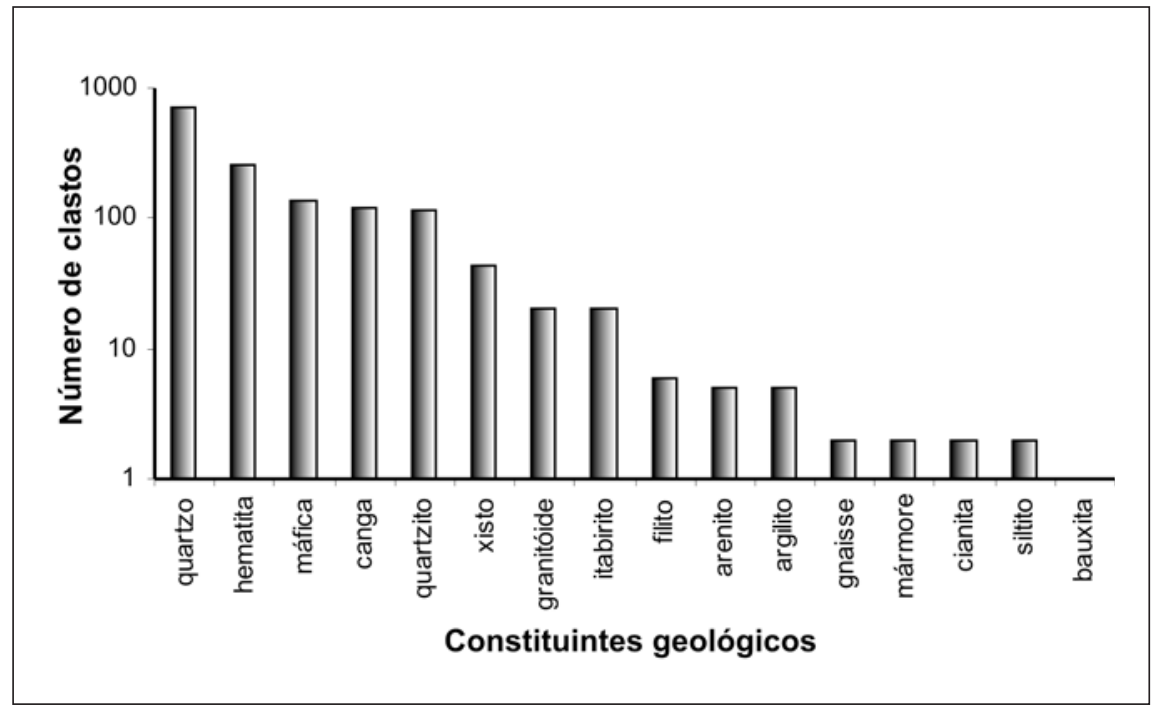

Figura 8 - Quantificação dos materiais geológicos encontrados nas amostras (escala logarítmica). Extraído de Lana (2004). 
tes antrópicas de sedimentos para o local estudado.

Para o setor de construção civil, o material mais explorado é o quartzito, extraído de forma artesanal na serra das Camarinhas, cerca de $10 \mathrm{~km}$ a montante da área estudada. Entretanto essa atividade tem caráter pontual, ao contrário da cobertura e calçamento das estradas vicinais.

Abaixo são listadas as principais hipóteses para a presença dos materiais mais abundantes no leito:

- Os clastos de quartzo podem ser provenientes, tanto de veios, dispersos ao longo da bacia, quanto das estradas de terra.

- Os clastos de hematita compacta são provenientes do Grupo Itabira (Supergrupo Minas), mas é possível que haja alguma contribuição por parte de afloramentos das formações ferríferas do Grupo Nova Lima (Supergrupo Rio das Velhas). Também pode haver contribuição a partir da cobertura das estradas. Porém, como o tráfego fragmenta essa cobertura e diminui a sua granulometria, é improvável que a maior parte dos materiais estudados nesse trabalho venha dessa fonte. Essa fonte só seria válida para os grãos que porventura tivessem sido transportados imediatamente após o calçamento das estradas, fato que não encontra suporte na área, tendo em vista o tráfego relativamente intenso naquela via de acesso.

- As rochas máficas, provavelmente metadiabásios, não aparecem na base cartográfica adotada. Portanto, os clastos devem provir de pequenos corpos intrusivos. O seu alto grau de arredondamento indica duas possibilidades:

1 - A abrasão dos fragmentos frescos ao longo de uma distância considerável, sugerindo que esses corpos estejam localizados nas proximidades das cabeceiras do rio das Velhas.

2 - A existência de afloramentos mais próximos ao local de coleta, onde a rocha tenha estado sob ação do intemperismo, favorecendo o desbaste das arestas dos clastos ao longo do curto trajeto de transporte.
- Os clastos de canga, couraças geradas sobre as formações ferríferas, têm atribuídas a si as mesmas áreas-fonte da hematita.

- Os clastos de quartzito têm área-fonte associada aos afloramentos de quartzito do Grupo Caraça (Supergrupo Minas). Aúnica ocorrência de quartzitos é descrita nas nascentes do rio das Velhas, distante cerca de $7 \mathrm{~km}$ a montante do segmento estudado.

\section{Conclusões}

Como o grau de arredondamento predominante nos clastos de quartzo é subanguloso, conclui-se que a maior parte dos grãos de quartzo encontrados é proveniente da dissecação de veios que foram observados em campo a menos de $500 \mathrm{~m}$ do segmento estudado.

A possibilidade de contribuição a partir das estradas de terra é descartada em função de o grande volume encontrado e de a granulometria analisada serem incompatíveis com o que está presente nas estradas (poucos clastos de quartzo com granulometria bastante superior à que predomina no segmento).

A área-fonte da hematita e da canga são as formações ferríferas do Grupo Itabira, que afloram a uma distância considerável da área de estudo, como confirmado pelo elevado grau de arredondamento dos clastos. A granulometria e o grau de arredondamento observados descartam a possibilidade de fontes próximas atribuídas ao rejeito utilizado nas estradas vicinais.

A presença de hematita compacta inalterada, em um segmento fluvial tão próximo às nascentes, indica a existência de áreas onde há exposição direta dessas rochas. Esse fato mostra que houve perda do manto de intemperismo (cangas). No entanto, os processos erosivos de disponibilização das hematitas e cangas são considerados naturais, já que não existem relatos de lavra das formações ferríferas do Grupo Itabira na região.

A área-fonte dos clastos de quartzito é a Formação Moeda, nas cabeceiras do rio das Velhas, pois o grau de arredondamento predominante indica o transporte dos clastos por uma distância considerável (de 7 a 10 km).
A abundância de clastos dessa rocha está parcialmente relacionada à lavra artesanal desse material na serra das Camarinhas. O desmatamento da vegetação nativa, somado à desagregação do quartzito e à acumulação de fragmentos menores, sem valor comercial, gera uma disponibilidade de sedimentos muito superior à natural.

A abundância de rochas máficas, no segmento estudado, não tem relação com atividades antrópicas. Porém, como a base cartográfica adotada no estudo não apresenta corpos dessa natureza e, além disso, mapas geológicos de maior detalhe da região (1:25.000) não apresentam corpos máficos próximos das drenagens a montante da área de estudo, é impossível precisar a sua proveniência.

\section{Referências bibliográficas}

ALKMIM, F. F., MARSHAK, S. Transamazonian orogeny in the southern São Francisco Craton region, Minas Gerais, Brazil: evidence for paleoproterozoic collision and collapse in the Quadrilátero Ferrífero. Precambrian Research, v. 90, p. 29-58, 1998.

COSTA, J. B. Estudo e classificação das rochas por exame macroscópico. (4.ed.). Coimbra: Fundação Calouste Gulbenkian, 1973. 196p.

DANA, J. D. Manual de mineralogía: tratado moderno para la enseñanza en universidades y escuelas especiales y para guía de ingenieros de minas y geólogos. (2.ed.). Barcelona: Editorial Reverté S.A., 1960. 598p. (Revisão de Hurlbut Jr, C. S. e tradução de Amorós, J. L.)

LANA, C. E. Cartografia integrada de ecossistemas lóticos (fluviais) no alto curso do rio das Velhas - MG. Ouro Preto: Departamento de Geologia, Escola de Minas, Universidade Federal de Ouro Preto, 2004. 175p. (Dissertação de Mestrado)

MABESOONE, J. M. Sedimentologia. Recife: Editora da UFPe, 1968. 478p.

MOURA, L. C. (coord.) Desenvolvimento de metodologia para recuperação de dados cartográficos para utilização em base de dados georreferenciados. Belo Horizonte: Cetec, 2000.

SCHUMM, S. A. The fluvial system. New York: Wiley - Interscience, 1977. 388p.

TUCKER, M. E. Sedimentary petrology: an introduction. Great Britain: Blackwell Scientific Publications, 1981. 252p.

Artigo recebido em 22/12/2006 e aprovado em 23/11/2007. 